\title{
Identification and Application of Drosophila Novel Bioactive Peptides dRYamides
}

\author{
Takanori Ida ${ }^{1, ~ *, ~ E r i ~ I w a m o t o " ~}{ }^{1}$, Takahiro Sato ${ }^{2}$, Masayasu Kojima \\ ${ }^{1}$ Department of Bioactive Peptides, Frontier Science Research Center University of Miyazaki, Miyazaki, Japan \\ ${ }^{2}$ Institute of Life Sciences, Kurume University, Fukuoka, Japan
}

\section{Email address:}

a0d203u@cc.miyazaki-u.ac.jp (T. Ida)

\section{To cite this article:}

Takanori Ida, Eri Iwamoto, Takahiro Sato, Masayasu Kojima. Identification and Application of Drosophila Novel Bioactive Peptides dRYamides. American Journal of Life Sciences. Special Issue: Biology and Medicine of Peptide and Steroid Hormones.

Vol. 3, No. 3-2, 2015, pp. 3-7. doi: 10.11648/j.ajls.s.2015030302.12

\begin{abstract}
The ligands of many orphan G protein-coupled receptors (GPCRs) remain to be identified, in both vertebrates and invertebrates, such as Drosophila melanogaster. Identification of their cognate ligands is critical for understanding the function and regulation of such GPCRs. Indeed, the discovery of bioactive peptides that bind GPCRs has enhanced our understanding of the mechanisms underlying many physiological processes. Here, we identified five endogenous ligands of the Drosophila orphan GPCRs, using functional assays and reverse pharmacological techniques. dRYamide-1 and -2 were found to be paired with the Drosophila neuropeptide Y (NPY)-like receptor (CG5811). Both dRYamide-1 and -2 contain a C-terminal RYamide. In vertebrates, RYamide motifs are found in NPY-family peptides. dRYamides were found to modulate feeding motivation in flies. These results suggest that deorphanizing the Drosophila orphan GPCRs might facilitate the elucidation of various physiological functions and identification of the ligands of orphan GPCRs in mammals.
\end{abstract}

Keywords: Novel Bioactive Peptide, Orphan GPCR, Drosophila

\section{Introduction}

Bioactive peptides are involved in a wide variety of biological phenomena, and it is anticipated that research on their activity may, in addition to its scientific significance, facilitate development of novel therapeutic effective products with few side effects. Thus, discovery of novel bioactive peptides can not only elucidate new biological functions, but can also facilitate drug development. Most endogenous bioactive peptides bond with seven transmembrane $G$ protein-coupled receptors (GPCRs), and activate $\mathrm{G}$ proteins within the cell. Through regulation of the nervous, circulatory, immune, digestive, and metabolic systems, GPCRs maintain organismal homeostasis, and are also involved in the regulation of various vital biological functions such as reproduction, growth, development, and sensory perception. The GPCR ligands, including peptides, identified to date show extremely diverse characteristics. GPCRs for which the endogenous ligands remain unknown are known as "orphan GPCRs;" there are approximately 180 types of orphan GPCRs (1). Since over half of the most highly sold medical products in the world target GPCRs, researchers across the globe are searching for the ligands of these orphan GPCRs.

\section{peptide extract from tissue}
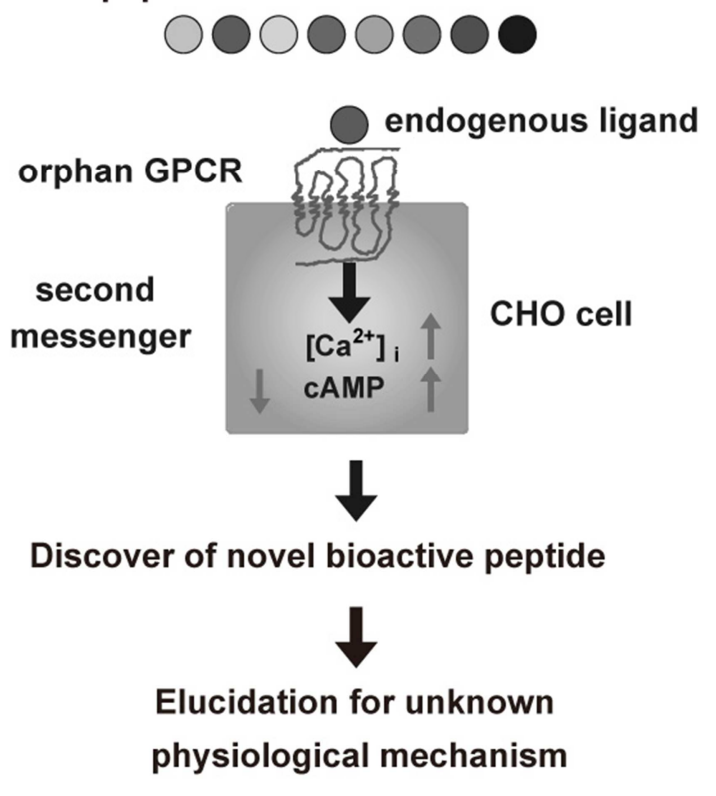

Figure 1. Schematic of search of a bioactive peptide using orphan receptor. 
However, in recent years discoveries of novel bioactive peptides for mammalian GPCRs have decreased. Here, we have attempted to identify the ligands of Drosophila GPCRs, in the hope that any ligands discovered might lead to identification of homologous mammalian bioactive peptides. We chose Drosophila because, as in mammals, the Drosophila genome database is extensive $(2,3)$, relatively simple techniques are available for genetic recombination and functional analysis, and many discoveries made using Drosophila can be applied to mammals, such as the Clock gene, per, and the Toll-like receptor, which is important in natural immunity (4-7). We aimed to identify novel bioactive peptides in Drosophila, to leverage those data to identify novel mammalian bioactive peptides, and finally to apply our knowledge for drug development.

First, we were interested in the role of this orphan receptor CG5811, because the novel bioactive peptide for this receptor may provide new insights into feeding mechanisms. The neuropeptide Y (NPY) family of peptides is widely conserved among vertebrates and has been implicated in feeding behavior (8-10). The vertebrate NPY family consists of NPY, peptide YY (PYY), and pancreatic polypeptide (PP), and these are grouped together based on structural similarities and evolutionary relationships. The C-terminal RYamide is conserved among peptides of the NPY family. In invertebrates, NPY homologs are designated as neuropeptide F (NPF), because the $\mathrm{C}$-terminal residue in all cases appears to be an amidated phenylalanine (F) residue, in contrast to the typical amidated tyrosine (Y) residue in vertebrate NPY family peptides (11). The vertebrate NPY receptors can be divided into 5 subgroups: Y1, Y2, Y4, Y5, and Y6. In Drosophila, Dm-NPFR (CG1147), the receptor for dNPF (CG10342), was cloned and found to be homologous to the vertebrate NPY receptor family of GPCRs (12). NPFR76F (CG7395), the receptor for sNPF (CG13968), has also been cloned $(13,14)$. Both receptors show structural similarities to vertebrate Y2 receptors and are expressed in the brain and gut. NPFR76F is not activated by other RFamide peptides, indicating that the fourth arginine from C-terminal is crucial for receptor activation (14). Another GPCR (CG5811; NepYR) was identified in Drosophila that could be activated by mammalian NPY and PYY and that shows some sequence similarities to NPY and NPF receptor (15). CG5811 did not specifically bind radiolabeled dNPF, in contrast to Dm-NPFR. The natural ligand has not yet been found for CG5811. We identified dRYamide-1 and dRYamide-2 (CG40733), the ligands for CG5811 in Drosophila melanogaster (16). We want to leverage the information of dRYamide to find novel bioactive peptides for mammal NPY receptors.

\section{Deorphanizing Strategies}

\subsection{Construction of Orphan GPCR-Expressing Cells}

Among mammalian orphan GPCRs, 50 to 100 types are theorized to possess ligands that may be bioactive peptides (17). We targeted these candidate peptide receptors, and chose similar receptors from the Drosophila orphan GPCR database (18). The cDNA of the target Drosophila orphan GPCR was ligated into an expression vector, and transfected into a Chinese hamster ovary (CHO) cell; after screening with G418, a cell line stably expressing the receptor was obtained. A peptide sample extracted from Drosophila was applied to this cell line stably expressing the receptor, and an assay system was constructed to measure intracellular changes in calcium or cAMP (Fig. 1).

\subsection{Purification of Drosophila Peptides}

Following boiling $400 \mathrm{~g}$ of flies to inactivate intrinsic proteases the peptides were extracted as described previously (19), and part of each gel filtration fraction was freeze-dried and used in the assay system. Active gel filtration fractions were repeatedly developed using ion-exchange high-performance liquid chromatography (HPLC) and reverse-phase (RP)-HPLC, and were finally isolated as single peaks. The structure of each isolated peptide was determined using a protein sequencer and mass spectrometry (Fig. 2).

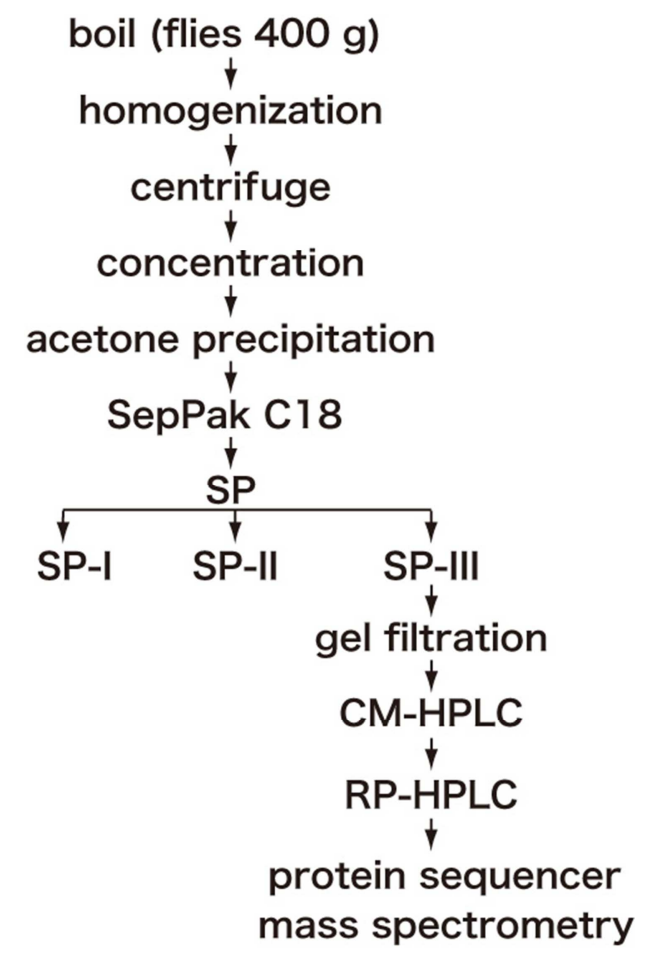

Figure 2. Flow chart of purification method of bioactive peptide.

\section{Structural Determination and Function of dRYamide}

\section{PVFFVASRY $-\mathrm{NH}_{2} \quad$ dRYamide-1 \\ NEHFFLGSRY $-\mathrm{NH}_{2} \quad$ dRYamide-2}

Figure 3. The structure of novel bioactive peptide dRYamide-1 and dRYamide-2. 
A

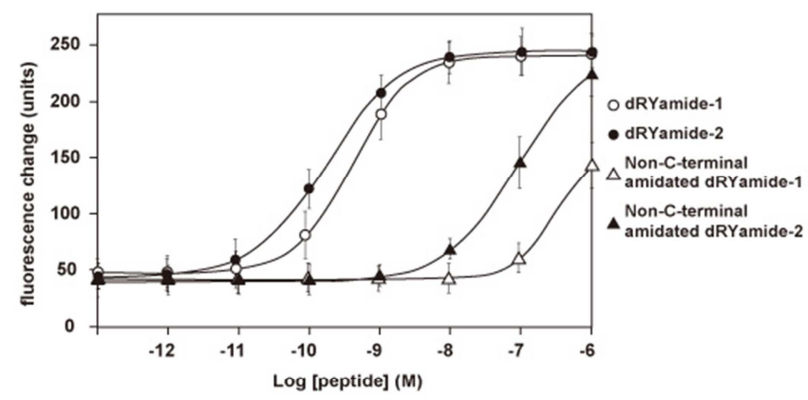

B

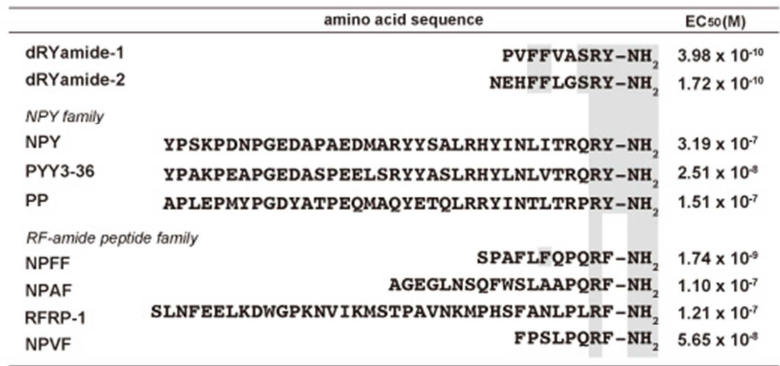

c
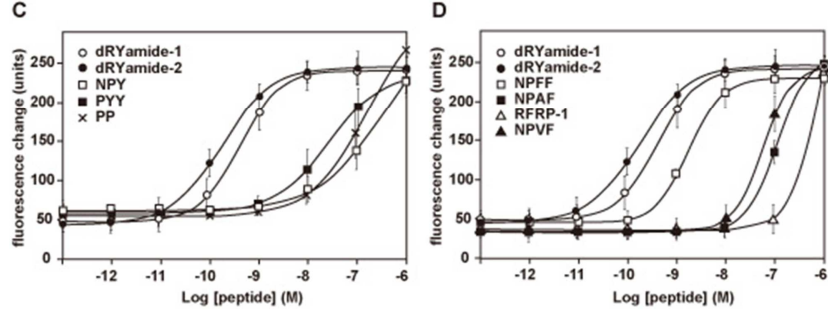

Figure 4. Pharmacological characterization of synthetic peptides using CG5811 stably expressed in $\mathrm{CHO}$ cells. (A) Dose-response relationships of changes in $\left[\mathrm{Ca}^{2+}\right]_{i}$ for dRYamides and non-C-terminal amidated dRYamides in CHO-CG5811 cells. (B) Sequences of synthetic peptides and half-maximal response concentrations $\left(E C_{50}\right)$ (M) for changes in $\left[\mathrm{Ca}^{2+}\right]_{i}$ by using CHO-CG5811. (C) (D) Dose-response relationships of changes in $\left[\mathrm{Ca}^{2+}\right]$ for various peptides. These data refer to Biochem. Biophys. Res. Commun (2011).

The Drosophila filtration sample fraction 51-54 increased intracellular calcium activity towards the Drosophila NPY-like receptor (CG5811), similar to mammalian NPY-family receptors. Fraction 51-54 was developed using HPLC, and the assay was repeated to isolate the peptide acting on the Drosophila NPY-like receptor. Two novel bioactive peptides were identified. They were named dRYamide-1 and dRYamide-2 (Fig. 3). For both dRYamide-1 and dRYamide-2, the C-terminal sequence was $\mathrm{SRY}-\mathrm{NH}_{2}$, and thus this was hypothesized to be the active site. When the amide group was deleted from the peptides, no activity was observed, indicating that a $\mathrm{C}$-terminal region that includes the amide group is vital for activity (Fig. 4A). A search of the cDNA database showed that dRYamide- 1 and dRYamide- 2 are derived from the same precursor, using a method of splicing that is also known in mammals. CG5811 has been shown to be expressed predominantly in the hindgut (by FlyAtlas; http://www.flyatlas.org/; University of Glasgow). The gene expression levels of dRYamides (CG40733) have not been published in FlyAtlas yet. We generated specific antisera against dRYamide-1 and dRYamide-2. In an immunohistochemical analysis using dRYamide-2-specific antiserum, dRYamide-2 was distributed in the larval central nervous system (CNS), midgut, and hindgut (Sano et al. paper in preparation). Therefore, dRYamides are suspected to be brain-gut peptides in insects. When an assay was conducted by using gel filtration samples of mouse brain extract, those induced robust increase in $\left[\mathrm{Ca}^{2+}\right]_{\mathrm{i}}$ in the CHO-Drosophila NPY-like receptor. The active fractions were observed in two peaks of fractions (numbers $47-49$ and 54-57). Two separate agonist activities were purified as a single peak in the final RP-HPLC. The amino acid sequences of the purified peptides were determined as neuropeptide Y (NPY) and neuropeptide FF (NPFF) (Fig. 4B). Synthetic dRYamide-1, dRYamide-2, mouse NPY-family peptide, and mouse NPFF were added to the CHO-Drosophila NPY-like receptor, and a comparative study was conducted to measure increases in the intracellular calcium activity (Fig. 4C, D). The synthetic dRYamide-1 and dRYamide-2 both showed extremely high activity. Unexpectedly, NPFF showed stronger activity for increasing intracellular calcium than the NPY-family peptide, of a strength comparable to that of dRYamide-1 and dRYamide-2. Mouse NPFF belongs to the RFamide peptide family, which is prevalent in mammals. Many peptides with arginine, phenylalanine, and amide groups in their C-termini are known, and many of these also have vital physiological functions. Tyrosine and phenylalanine are similar in structure, and Phe 6 corresponds to the Tyr 6 of dRYamide, and it could potentially display strong activity. Based on reports published to date and current phylogenetic data, it is unclear whether or not the Drosophila NPY-like receptor is homologous to the receptor for the NPY-family peptide

or the receptor for NPFF (Fig. 5). A study of whether dRYamide is more closely related to NPY in mammals or

NPFF should be conducted in future. NPY-family peptides are important peptides that regulate eating behavior in mammals. NPFF is involved in regulation of pain sensation. The physiological effect of dRYamide remains unknown, but when it was administered to blow flies, the proboscis extension reflex (PER), thought to be the motivation for eating behavior, was strongly restrained. In flies and certain other insects, the PER test has long been used to investigate behavioral sensitivity to phagostimulative tastes (20). Flies extend their proboscis when the contact chemosensilla on their labella detect sweetness of sugar above a certain threshold concentration. Thus, we estimated appetite or feeding motivation of the fly by the PER test to sucrose, in which the threshold concentration of sucrose was evaluated as an indicator of feeding sensitivity. The present study showed that the injection of dRYamide-1 increased the threshold for feeding on a sucrose solution. These data suggest that dRYamides attenuated the feeding motivation of the flies. Thus, dRYamide may have potential for application to extermination of harmful insects. Next, potential applications of dRYamide in mammals were examined. When dRYamide-1 and dRYamide-2 were applied to $\mathrm{CHO}$ cells expressing the mouse NPY receptors or the NPFF receptors, neither 
increased intracellular calcium activity, cyclic AMP, or showed a restraining effect. However, when dRYamide-2 was administered to the mouse intra-abdominally, eating behavior and intestinal movement were significantly decreased. Additionally, when dRYamide-2 was administered intravenously to a rat, the firing rate of the stomach vagus nerve efferent pathway, as well as blood pressure and heart rate, increased (unpublished data). Generally, if the parasympathetic nervous system is estimulated, both blood pressure and heart rate decrease; in this case, both increased, and it may be that in mammals the effect of dRYamide is non-specific. However, a previously unknown mechanism may be involved. If future investigations can reveal which mammal receptor dRYamide acts on, and what effect it produces, they may facilitate drug development.

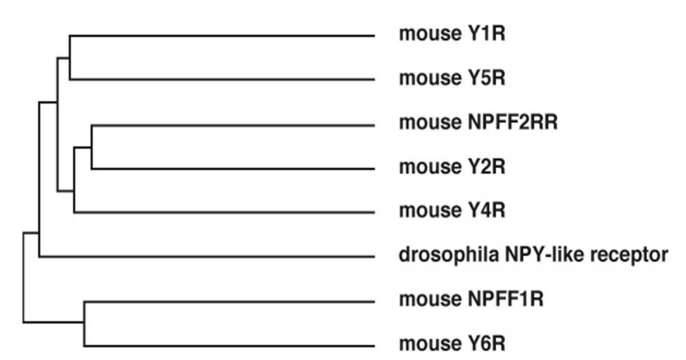

Figure 5. Relation with drosophila NPY-like receptor (CG5811), mouse NPY and a NPFF receptor.

\section{Conclusion}

To facilitate discovery of novel mammalian bioactive peptides, a search was conducted using Drosophila as a model organism, and then applications to mammals were studied. Novel bioactive peptides were discovered in Drosophila, but did not lead to identification of novel mammalian peptides. However, the Drosophila novel bioactive peptides discovered were detected to have physiological effects in rats and mice. In the future, although research into this area in mammals is somewhat stymied, it is anticipated that novel bioactive peptides will be discovered, their functions analyzed, and that drug development may follow.

\section{Acknowledgements}

This work was financially supported in part by Grant-in-Aid for Scientific Research on Innovative Areas from Japan Society for the Promotion of Science (22126003 to M.K., and 25126720 to TI), Grant-in-Aid for Scientific Research $(C)$ from the Ministry of Education, Culture, Sports, Science and Technology of Japan (26450471 to TI), and MEXT-Supported Program for the Strategic Research Foundation at Private Universities (M.K.)

\section{References}

[1] Vassilatis DK, Hohmann JB, Zeng H, Li F, Ranchalis JE, Mortrud MT, Brown A, Rodriguez SS, Weller JR, Wright AC, Bergmann JE, Gaitanaris G. The G protein-coupled receptor repertories of human and mouse, Proc Natl Acad Sci USA 2003; 100: 4903-4908.

[2] Adams MD, Celniker SE, Holt RA, Evans CA, Gocayne JD, Amanatides PG, Scherer SE, Li PW, Hoskins RA, Galle RF. The genome sequence of Drosophila melanogaster, Science 2000; 287: 2185-2195.

[3] Brody T, Cravchik A. Drosophila melanogaster G protein-coupled receptors, J Cell Biol. 2000; 150: 83-88.

[4] Konopka RJ, Benzer S. Clock mutants of Drosophila melanogaster, Proc Natl Acad Sci U S A, 1971; 68(9): 2112-2116.

[5] Anderson KV, Jürgens G, Nüsslein-Volhard C. Establishment of dorsal-ventral polarity in the Drosophila embryo: genetic studies on the role of the Toll gene product,Cell 1985; 42(3): 779-789.

[6] Lemaitre BI, Nicolas E, Michaut L, Reichhart JM, Hoffmann JA. The dorsoventral regulatory gene cassette spätz le/Toll/cactus controls the potent antifungal response in Drosophila adults, Cell 1996; 86(6): 973-983.

[7] Poltorak AI, He X, Smirnova I, Liu MY, Van Huffel C, Du X, Birdwell D, Alejos E, Silva M, Galanos C, Freudenberg M, Ricciardi-Castagnoli P, Layton B, Beutler B. Defective LPS signaling in $\mathrm{C} 3 \mathrm{H} / \mathrm{HeJ}$ and $\mathrm{C} 57 \mathrm{BL} / 10 \mathrm{ScCr}$ mice: mutations in Tlr4 gene,Science 1998; 282(5396): 2085-2088.

[8] Beck B. KO's and organisation of peptidergic feeding behavior mechanisms, Neurosci. Biobehav. Rev. 2001; 25: 143-158.

[9] Williams G, Bing C, Cai XJ, Harrold JA, King PJ, Liu XH. The hypothalamus and the control of energy homeostasis: Different circuits, different purposes, Physiol. Behav. 2001; 74: 683-701.

[10] Zimanyi IA, Fathi Z, Poindexter GS. Central control of feeding behavior by neuropeptide Y, Curr. Pharm. Des. 1998; 4: 349-366.

[11] Nässel DR, Wegener C. A comparative review of short and long neuropeptide F signaling in invertebrates: Any similarities to vertebrate neuropeptide Y signaling? Peptides. 2011; 326(6): 1335-55.

[12] Garczynski SF, Brown MR, Shen P, Murray TF, Crim JW. Characterization of a functional neuropeptide $\mathrm{F}$ receptor from Drosophila melanogaster, Peptides. 2002; 23: 773-780.

[13] Feng G, Reale V, Chatwin H, Kennedy K, Venard R, Ericsson C, Yu K, Evans PD, Hall LM. Functional characterization of a neuropeptide F-like receptor from Drosophila melanogaster, Eur. J. Neurosci. 2003; 18: 227-238.

[14] Mertens I, Meeusen T, Huybrechts R, Loof AD, Schoofs L. Characterization of the short neuropeptide $\mathrm{F}$ receptor from Drosophila melanogaster, Biochem. Biophys. Res. Commun. 2002; 297: 1140-1148.

[15] Li XJ, Wu YN, North RA, Forte M. Cloning, functional expression, and developmental regulation of a neuropeptide $\mathrm{Y}$ receptor from Drosophila melanogaster, J. Biol. Chem. 1992; 267: 9-12.

[16] Ida T, Takahashi T, Tominaga H, Sato T, Kume K, Ozaki M, Hiraguchi T, Maeda T, Shiotani H, Terajima S, Sano H, Mori K, Yoshida M, Miyazato M, Kato J, Murakami N, Kangawa K.Kojima M. Identification of the novel bioactive peptides dRYamide-1 and dRYamide-2, ligands for a neuropeptide Y-like receptor in Drosophila, Biochem Biophys Res Commun. 2011; 410: 872-77. 
[17] Civelli O, Nothacker HP, Saito Y, Wang Z, Lin SH, Reinscheid RK. Novel neurotransmitters as natural ligands of orphan G-protein-coupled receptors, Trends Neurosci. 2001; 24: 230-237.

[18] Brody T, Cravchik A. Drosophila melanogaster G protein-coupled receptors, J Cell Biol. 2000; 150: 83-88.

[19] Ida T, Miyazato M, Lin XZ, Kaiya H, Sato T, Nakahara
K,Murakami N, Kangawa K, Kojima M. Purification and characterization of caprine ghrelin and its effect on growth hormone release, J. Mol. Neurosci. 2010; 42: 99-105.

[20] Nisimura T, Seto A, Nakamura K, Miyama M, Nagao T, Tamotsu S, Yamaoka R, Ozaki M. Experiential effects of appetitive and nonappetitive odors on feeding behavior in the blowfly, Phormia regina: A putative role for tyramine in appetite regulation, J. Neurosci. 2005; 25: 7507-7516. 